\title{
DESENVOLVIMENTO DE UM SISTEMA PARA ALGUNS EXERCÍCIOS DE GINÁSTICA LABORAL UTILIZANDO O SENSOR DE MOVIMENTO KINECT
}

\section{DEVELOPMENT OF A SYSTEM FOR SOME PREVENTION EXERCISES USING THE MOTION SENSOR KINECT}

Marco Antônio da Silva Ribeiro; Francisco Assis da Silva; Daniela Tereza Ascêncio Russi; Mário Augusto Pazoti; Leandro Luiz de Almeida; Danillo Roberto Pereira

Faculdade de Informática - FIPP, Universidade do Oeste Paulista - UNOESTE e-mail: mahribeiro@unoeste.edu.br; \{chico, daniela, mario, Ilalmeida, danilopereira\}@unoeste.br

RESUMO - Comumente funcionários apresentam algum desconforto físico ocasionado devido ao sedentarismo ou devido à atividade desempenhada com movimentos repetitivos. O propósito deste trabalho é o desenvolvimento de um sistema que facilite, de maneira monitorada, funcionários a realizar exercícios de ginástica laboral para prevenirem riscos de lesões. A ideia é que funcionários possam definir seus próprios horários para a prática da ginástica laboral, inclusive realizar os exercícios em sua própria residência, sendo os resultados armazenados para consulta posteriormente. O sistema serve como ferramenta de apoio para que o educador físico consiga acompanhar um maior número de funcionários. Para saber se o movimento foi feito de maneira correta, o sistema utiliza uma comparação de ângulos relacionados aos movimentos das juntas do corpo humano comparando com os ângulos de um movimento pré-definido. Nem todos os exercícios são possíveis de serem acompanhados pelo sistema devido às limitações do sensor Kinect.

Palavras-chave: Kinect; Ginástica Laboral; Atividades.

ABSTRACT - Employees commonly show some physical discomfort caused due to inactivity or due to activity performed with repetitive movements. The purpose of this work is to develop a system to facilitate, so monitored employees to perform exercises of gymnastics to prevent risk of injury. The idea is that employees can set their own schedules to practice gymnastics, including performing the exercises in your own home, with the results stored for viewing later. The system serves as a support tool for the physical educator can monitor a larger number of employees. To know if the move was done right, the system uses a comparison of angles related to the movements of the joints of

Recebido em: 19/10/2014 Revisado em: 07/12/2014 Aprovado em: 18/12/2014 the human body compared to the angles of a pre-defined motion. Not all exercises are likely to be accompanied by the system due to the limitations of the Kinect sensor.

Keywords: Kinect; Preventive Exercise; Activitys. 


\section{INTRODUÇÃO}

Nunca a sociedade teve tantas oportunidades para viver bem, saudável e com longevidade como nos dias de hoje. Ao mesmo tempo, nunca o homem esteve tão sedentário e sem harmonia. Sem o corpo sadio e com a mente comprometida, o ser humano perde justamente o que mais necessita: a disposição para produzir, conviver e viver bem (SANTOS, 2008). É nesse contexto que age a ginástica laboral, que por meio de exercícios físicos proporciona diversos benefícios para os trabalhadores e, consequentemente, para as empresas.

Algumas empresas já oferecem profissionais de educação física responsáveis por incentivar e monitorar as atividades. Entretanto, alguns funcionários ainda encontram certa resistência quanto à implantação de programas de ginástica laboral. Mesmo conscientizados dos possíveis benefícios dessa prática, alguns justificam essa resistência com motivos relacionados a constrangimentos por exposição no momento da prática, por acharem indevido esse tipo de movimentação em momentos de trabalho e falta de crença nos resultados (SOARES; ASSUNÇÃO; LIMA, 2006).

O uso de consoles domésticos na prática de exercícios aumenta a motivação do usuário para realizar o exercício e o índice de acerto dos movimentos feitos por ele
(CHANG; CHEN; HUANG, 2011). Segundo Lange et al. (2011), graças à evolução tecnológica é possível usar videogames domésticos como ferramentas para prática de exercícios. Existem estudos que comprovam que a fisioterapia utilizando o Kinect é até mais eficaz que os métodos convencionais (CHANG; CHEN; HUANG, 2011).

Para Ferraz e Yamashita (2012), o Kinect é um aparelho no qual o público tem relativamente fácil acesso e que pode ser usado sem que o usuário possua o videogame Xbox 360. O Kinect é uma ferramenta que permite captar os movimentos de uma pessoa e utilizá-los em uma interface no computador como, por exemplo, em um jogo (XBOX, 2012).

Segundo Paula (2011), o Kinect é constituído de um conjunto de câmeras e sistema de projeção que retorna uma informação bastante exata de cor e da profundidade associada a cada ponto. O aparelho destaca-se também por devolver a posição $(x, y, z)$ de um conjunto de pontos associados às juntas principais do corpo humano (cabeça, ombros, cotovelos, joelhos, por exemplo).

O principal destaque do dispositivo está na possibilidade de uso de seu sensor de profundidade em jogos e aplicativos, obtendo com bastante exatidão a distância 
de cada pixel de uma imagem em relação ao sensor (PAULA, 2011).

A Microsoft lançou sua própria plataforma de desenvolvimento, voltada a computadores rodando o Windows 7. O SDK (Software Development Kit) oficial possibilita que os desenvolvedores $\mathrm{C}++, \mathrm{C \#}$ ou Visual Basic acessem as informações das câmeras do sensor e o rastreamento do esqueleto, como as plataformas abertas, mas também dá o poder ao programador de criar aplicativos que usem o reconhecimento de fala (PAULA, 2011).

A proposta deste trabalho é utilizar a tecnologia como meio de se conseguir uma melhor qualidade de vida para funcionários de uma empresa, no que se refere a facilitar a prática de exercícios de ginástica laboral para o bem estar desses funcionários. Utilizando o sensor Kinect, é possível auxiliar os funcionários na prática de ginástica laboral e, ao mesmo tempo, monitorar se os movimentos estão sendo executados de forma correta e armazenar os dados dos exercícios para consulta posteriormente.

Com o auxílio do sistema desenvolvido nesse trabalho, o usuário pode realizar a atividade, de maneira monitorada, em diversos horários e locais, e o profissional responsável consegue abranger um maior número de funcionários.

O sistema utiliza a tecnologia do sensor Kinect, que vem sendo usado com frequência em diversas áreas, desde ajudar crianças com autismo, até ajudar doutores em salas de operações (XBOX, 2012).

As demais seções deste trabalho estão organizadas da seguinte maneira: na Seção 2 é apresentada a Ginástica Laboral e suas definições; na Seção 3 é apresentada a metodologia e a forma como a aplicação foi desenvolvida; na Seção 4 são apresentados os experimentos realizados; na Seção 5 estão os resultados e discussões; na Seção 6 encontra-se a conclusão sobre este trabalho.

\section{GINÁSTICA LABORAL}

Segundo Alves (2000), discutindo a questão da associação da Ginástica Laboral como medida preventiva, afirma que a Ginástica Laboral é uma das ferramentas mais utilizadas nos grupos em que a atuação coletiva é possível, não sendo única solução para os problemas das empresas. Sua utilização sem critérios não gera efeitos duradouros, podendo até levar ao agravamento e surgimento de novos casos de LER (Lesão por Esforços Repetitivos).

De acordo com Polito e Bergamaschi (2002), os objetivos da Ginástica Laboral são: promover a saúde, corrigir os vícios posturais, diminuir o absenteísmo e a procura ambulatorial, melhorar a condição física geral, aumentar o ânimo e disposição para o trabalho, promover o autocondicionamento orgânico, promover a 
consciência corporal, melhorar o relacionamento interpessoal, prevenir a fadiga muscular e prevenir a LER.

Para Longen (2003), dentre as ações praticadas na busca da prevenção de LER/DORT (Lesões por Esforços Repetitivos / Distúrbios Osteomusculares Relacionados ao Trabalho), a Ginástica Laboral está presente em várias empresas, sendo proposta como uma das medidas preventivas e, também, recebe a atribuição de ser a principal medida de enfrentamento.

Entre as medidas encontradas para minimizar a ocorrência da LER, a introdução da Ginástica Laboral passou a ser comum nos ambientes de trabalho industrializados, passando a ocupar um grande espaço dentro das iniciativas de prevenção propostas pelos diferentes profissionais que atuam na saúde do trabalho (LONGEN, 2003).

A Ginástica Laboral pode ser classificada quanto ao horário de execução e quanto ao objetivo que possui. A primeira classificação divide o expediente de trabalho em três momentos: preparatório (no começo do expediente de trabalho), o compensatório (no meio do expediente), e o relaxante (no fim do expediente). A segunda classificação diferencia os objetivos para a aplicação da ginástica em: Ginástica Laboral preparatória (prepara o trabalhador para atividades de força, velocidade ou resistência), ginástica de compensação (previne a instalação de vícios posturais), ginástica corretiva (restabelece o equilíbrio muscular e articular) e ginástica de conservação ou manutenção (mantém o equilíbrio fisiomorfológico) (ZILLI, 2002; MENDES; LEITE, 2004).

Ginástica Laboral preparatória ou de aquecimento é a ginástica realizada no início da jornada de trabalho, ou seja, no início do turno da manhã, da tarde ou da noite; normalmente realizada no posto de trabalho. Esta é classificada desta forma, visto que prepara o trabalhador para atividades de velocidade, força e resistência. A mesma ativa fisiologicamente o organismo, melhora o nível de concentração e disposição, elevando a temperatura do corpo, oxigenando os tecidos e aumentando a frequência cardíaca. Tem a duração aproximada de 10 a 12 minutos. Inclui exercícios de coordenação, equilíbrio, concentração, flexibilidade e resistência muscular (ZILLI, 2002; MENDES; LEITE, 2004).

Na Ginástica laboral compensatória, sua execução objetiva impedir que se instalem os vícios posturais das atividades da vida diária e do ambiente de trabalho. Esta pausa deve utilizar atividades compensatórias específicas para cada setor da empresa, de acordo com as características do ambiente de trabalho. Desta forma esta ginástica alcança o equilíbrio físico e mental para a execução das tarefas. Fisiologicamente a sua principal finalidade é compensar todo e 
qualquer tipo de tensão muscular adquirido pelo uso excessivo ou inadequado das estruturas musculo ligamentares. Tem 0 objetivo de melhorar a circulação com a retirada de resíduos metabólicos, modificarem a postura no trabalho, reabastecer os depósitos de glicogênio e prevenir a fadiga muscular. São sugeridos exercícios de alongamento e flexibilidade, respiratórios e posturais com duração de 5 a 10 minutos durante a jornada de trabalho (ZILLI, 2002; MENDES; LEITE, 2004).

Ginástica laboral de relaxamento é a Ginástica Laboral realizada no final da jornada de trabalho, com duração aproximada de 10 a 12 minutos, tem como objetivo a redução do estresse, alívio das tensões, redução dos índices de desavenças no trabalho e em casa, com consequente melhora da função social. São realizadas automassagens, exercícios respiratórios, exercícios de alongamento, flexibilidade e meditação (ZILLI, 2002; MENDES; LEITE, 2004).

A Ginástica Laboral vem por meio de exercícios físicos, proporcionar diversos benefícios para os trabalhadores e, consequentemente, para as empresas. Se realizada de forma adequada e bem orientada, a ginástica proporciona melhora em todos os aspectos que envolvem o bem estar do ser humano e, com isso, contribui para o aumento da produtividade e do lucro para as instituições empresariais (KIMURA et al., 2010).

\section{METODOLOGIA}

Toda atividade de ginástica laboral a ser executada no sistema precisa ser previamente cadastrada e, preferencialmente, com a ajuda de um profissional da área (educador físico), pois esse profissional tem conhecimento de como o exercício deve ser realizado. Durante a gravação da atividade a ser cadastrada, o sensor Kinect captura a imagem da pessoa para que seja possível identificar o esqueleto com as articulações já mapeadas, conforme a Figura 1.

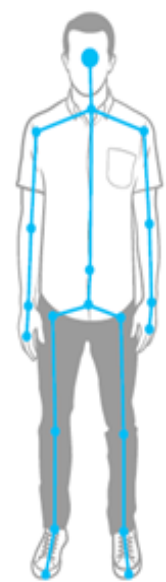

Figura 1. Articulações mapeadas através do sensor Kinect.

Quando inicia a gravação do exercício de Ginástica Laboral, é feita a verificação do mapeamento do esqueleto, também é verificado o mapeamento de cada uma das articulações e, a partir daí, decide se o esqueleto será armazenado ou descartado. O 
esqueleto será descartado sempre que não for mapeado ou possuir apenas informação sobre a posição do usuário. Apenas o esqueleto que for mapeado corretamente e, fornecer além da posição do usuário, as posições de todas as articulações, é utilizado para verificar se o mapeamento de cada articulação está claramente visível ou não. No caso do mapeamento de uma articulação não estar claramente visível, significa que o Kinect está deduzindo uma posição.

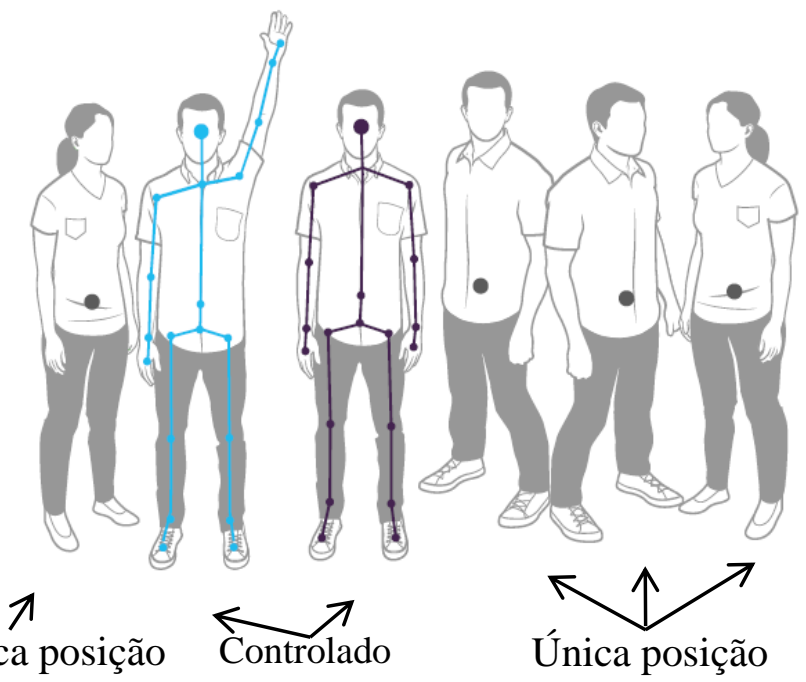

(a)

O sensor Kinect tem a capacidade de mapear, ao mesmo tempo, as articulações de até duas pessoas e detectar até seis pessoas (XBOX, 2012). Para cada pessoa, o sensor tem a capacidade de mapear até vinte articulações no modo padrão em pé (Figura 2 (b)) e até dez articulações da parte superior do corpo no modo sentado (Figura 2 (c)) e cada conjunto de articulações mapeado é denominado como esqueleto (TANJI et al., 2013).

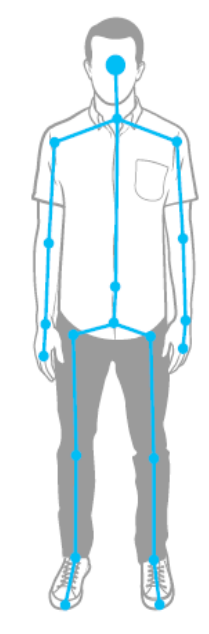

(b)

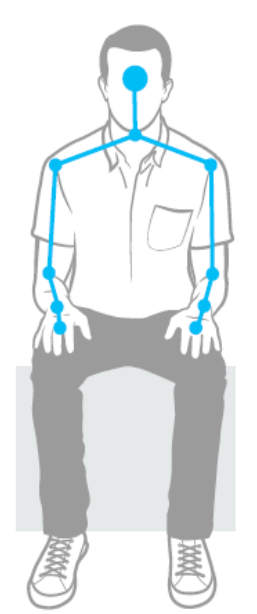

(c)

Figura 2. Pontos e capacidade de mapeamento do sensor Kinect.

Fonte: (TANJI et al., 2013)

Cada esqueleto tem um estado de mapeamento que pode ser dos tipos (Figura $2(a)):$

- Controlado: O esqueleto foi mapeado corretamente e poderá fornecer a posição de todas as vinte articulações;

- Não controlado: O esqueleto não foi mapeado;
- Única posição: O esqueleto possui apenas informações sobre a posição do usuário, mas não possui informações das articulações.

E cada articulação tem um estado de mapeamento que pode ser dos tipos:

- Controlado: A articulação está claramente visível; 
- Não controlado: A articulação não foi mapeada. Exemplo: Articulações inferiores no modo sentado;

- Deduzido: A articulação não está claramente visível e o Kinect está inferindo a posição.

Para cada articulação é possível obter o valor de $x$ e $y$ que correspondem às coordenadas de onde cada articulação foi mapeada na tela. Durante a gravação do exercício é mostrado na tela o esqueleto, que terá as articulações com estado controlado desenhadas na tela na cor azul e as articulações com estado deduzido desenhadas na tela na cor amarela, possibilitando saber em tempo real se os movimentos estão sendo cadastrados corretamente ou não. Na Figura 3, a articulação do braço esquerdo não está claramente visível e, por isso aparece na cor amarela, para mostrar que o Kinect está inferindo a posição.

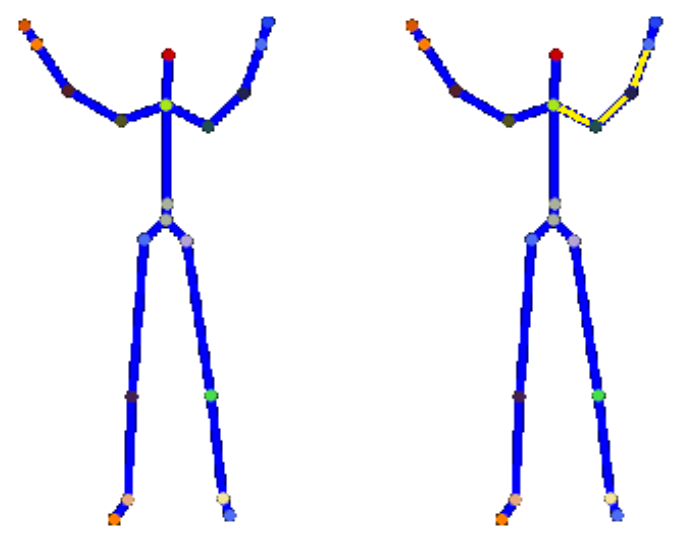

Figura 3. Articulações com estado controlado e deduzido.

Fonte: (Autor).
A princípio os exercícios foram cadastrados onde apenas os pontos $x$ e $y$ iriam ser usados posteriormente para o monitoramento do exercício. Após investigação sobre a execução dos exercícios, ficou evidente que a maneira correta de se executar os exercícios dependia da angulação de cada articulação e não apenas dos pontos. Sendo assim, o cadastro foi desenvolvido de maneira que são exibidos, durante a gravação, os ângulos das articulações, calculados utilizando a Equação (1) (TANJI et al., 2013).

$$
\theta=\operatorname{arcos}\left[\frac{x a \cdot x b+y a \cdot y b}{\sqrt{x a^{2}+y a^{2}} \cdot \sqrt{x b^{2}+y b^{2}}}\right]
$$

Após gravar um exercício no banco de dados (Seção 3.1), é possível iniciar sua execução. Para iniciar a execução de um exercício, primeiramente deve-se selecionar uma sessão, que é um nome dado a uma série de exercícios, e em seguida, deve-se escolher um exercício que pertence à sessão. Após isso, o sensor Kinect procura por um esqueleto com estado controlado, e assim que reconhece o primeiro esqueleto, inicia a execução do exercício. É exibido na tela o esqueleto do exercício escolhido, sobreposto à imagem que está sendo capturada pelo sensor Kinect em tempo real. A Figura 4 mostra um exemplo de um esqueleto de um exercício escolhido que será sobreposto à imagem da pessoa. 


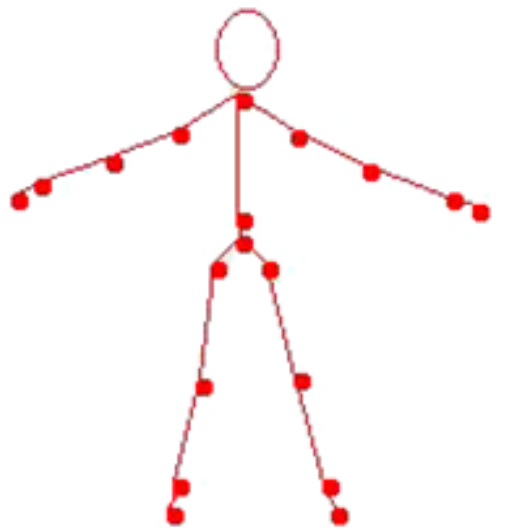

Figura 4. Esqueleto de um exercício.

Fonte: (Autor)

Como o objetivo é realizar o movimento com as mesmas angulações de cada articulação do exercício armazenado, que está sendo mostrado como um esqueleto na tela, faz-se necessário que o esqueleto e a pessoa capturada pelo sensor Kinect tenham o mesmo centro para que o esqueleto sempre acompanhe a imagem da pessoa capturada. Para que isso fosse possível, a cada ciclo de apagar e desenhar novamente o esqueleto, é calculada a média entre os pontos $y$ centrais, que são as juntas da cabeça (head), centro dos ombros (shoulder center), espinha (spine) e centro dos quadris (hip center) e calculado os mesmos dados das juntas da imagem real, e com a diferença entre os dois, o esqueleto é reposicionado sobre a imagem real. Durante a execução do exercício é possível saber se o exercício está sendo executado de forma correta ou não, em tempo de execução. Para o cálculo da margem de erro aceitável, a princípio foi utilizada a fórmula de distância euclidiana, conforme a equação (2) (TANJI et al., 2013).

$$
\text { dist }=\sqrt{\left(x_{1}-x_{2}\right)^{2}+\left(y_{1}-y_{2}\right)^{2}}
$$

Após a percepção de que essa não seria a melhor forma pelo fato da comparação ser ponto a ponto, foram utilizados os ângulos das articulações para monitorar a execução dos exercícios, pois através dos ângulos é possível comparar corretamente o que foi gravado com o que foi executado. Sempre que um esqueleto vai ser desenhado na tela, são calculados os ângulos das articulações da imagem real e do esqueleto previamente cadastrado (Equação 1) e, cada articulação pode ser desenhada, na tela do computador, em verde se o ângulo estiver dentro da margem de erro ou vermelho se estiver fora da margem de erro.

Após a execução de um exercício, é possível exibir o resultado do que foi executado. O resultado consiste em um resultado parcial, sendo exibida a porcentagem de acerto de cada uma das vinte articulações do esqueleto e o resultado completo, onde é possível acompanhar a diferença de cada ponto $x$ e $y$ que foi executado e quais eram os pontos que deveriam realmente ser executados. As Figuras 8 e 9 da Seção 4 mostram como o resultado pode ser apresentado para o usuário. 


\subsection{Persistência dos dados}

Para que os exercícios salvos não sejam armazenados apenas em memória e perdidos sempre que a aplicação for reiniciada, foi necessário que os dados fossem armazenados em um banco de dados. Com o armazenamento, é possível que os exercícios sejam recuperados sempre que necessário. O banco de dados utilizado foi o Microsoft SQL Server 2008. Após o término da gravação de um exercício deve-se atribuir um nome ao exercício e atribuir o exercício a uma sessão. É gravado no banco o nome do exercício, a sessão que o exercício corresponde e todas as coordenadas $x$ e $y$, de cada articulação (Tabela 1), capturadas durante a gravação dos movimentos. A figura 5 mostra o modelo lógico do banco.

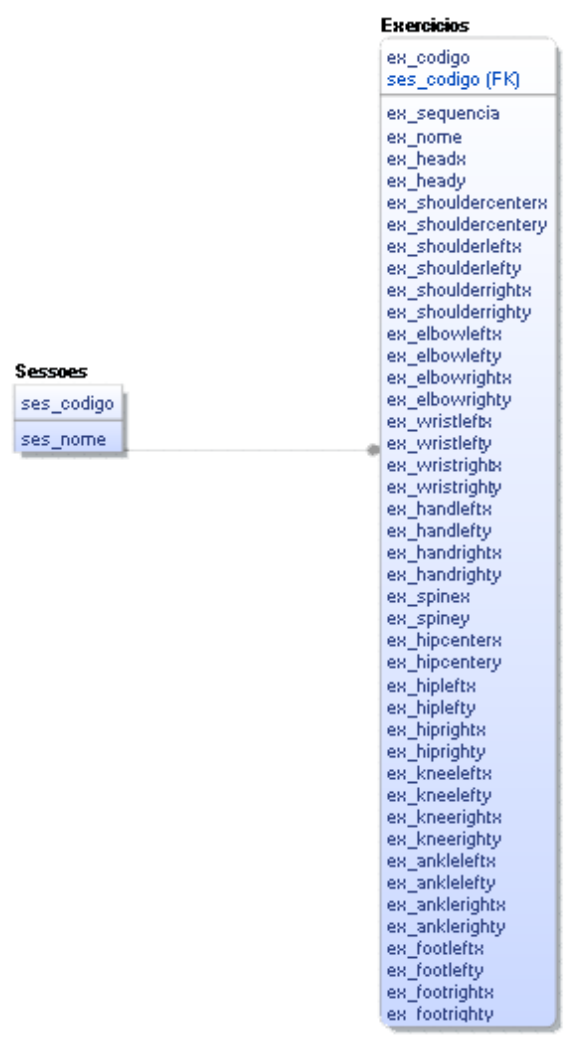

Figura 5. Modelo lógico do banco de dados.
Fonte: (Autor).

\section{2 Ângulos}

É através de comparações de ângulos calculados por meio das articulações (Equação 1) do corpo humano que é possível definir se o exercício foi executado corretamente ou não.

A Figura 6 mostra e enumera todos os ângulos que podem ser capturados pelo sensor Kinect e as Tabelas 1 e 2 mostram, respectivamente, o nome das articulações e a relação dos ângulos utilizados no cadastro e monitoramento do exercício (TANJI et al., 2013).

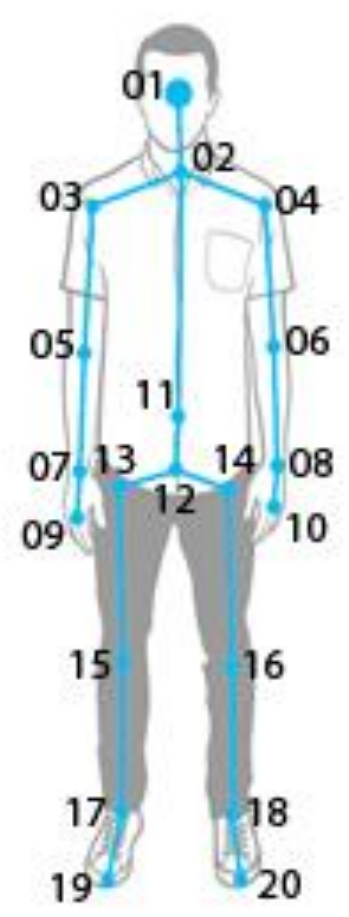

Figura 6. Articulações capturadas pelo sensor Kinect enumeradas.

Fonte: (TANJI et al., 2013). 
Tabela 1. Nomes das articulações capturadas pelo sensor Kinect.

\begin{tabular}{|l|l|}
\hline No & \multicolumn{1}{|c|}{ Nome } \\
\hline 01 & Cabeça (head) \\
\hline 02 & Centro dos Ombros (shouldercenter) \\
\hline 03 & Ombro Esquerdo (shoulderleft) \\
\hline 04 & Ombro Direito (shoulderright) \\
\hline 05 & Cotovelo Esquerdo (elbowleft) \\
\hline 06 & Cotovelo Direito (elbowright) \\
\hline 07 & Pulso Esquerdo (wristleft) \\
\hline 08 & Pulso Direito (wristright) \\
\hline 09 & Mão Esquerda (handleft) \\
\hline 10 & Mão Direita (handright) \\
\hline 11 & Coluna Vertebral (spine) \\
\hline 12 & Centro dos Quadris (hipcenter) \\
\hline 13 & Quadril Esquerdo (hipleft) \\
\hline 14 & Quadril Direito (hipright) \\
\hline 15 & Joelho Esquerdo (kneeleft) \\
\hline 16 & Joelho Direito (kneeright) \\
\hline 17 & Tornozelo Esquerdo (ankleleft) \\
\hline 18 & Tornozelo Direito (ankleright) \\
\hline 19 & Pé Esquerdo (footleft) \\
\hline 20 & Pé Direito (footright) \\
\hline
\end{tabular}

Tabela 2. Relação dos pontos utilizados para calcular os ângulos de cada articulação.

\begin{tabular}{|l|l|l|}
\hline \multicolumn{3}{|c|}{ Relação Ângulos x Articulações } \\
\hline \multicolumn{1}{|c|}{ Ponto 1 } & \multicolumn{1}{|c|}{ Ponto 2 } & \multicolumn{1}{c|}{ Ponto 3 } \\
\hline Cabeça & - & - \\
\hline Centro dos Ombros & Cabeça & Coluna Vertebral \\
\hline Ombro Esquerdo & Centro dos Ombros & Cotovelo Esquerdo \\
\hline Ombro Direito & Centro dos Ombros & Cotovelo Direito \\
\hline Cotovelo Esquerdo & Ombro Esquerdo & Pulso Esquerdo \\
\hline Cotovelo Direito & Ombro Direito & Pulso Direito \\
\hline Pulso Esquerdo & Cotovelo Esquerdo & Mão Esquerda \\
\hline Pulso Direito & Cotovelo Direito & Mão Direita \\
\hline Mão Esquerda & - & - \\
\hline Mão Direita & - & - \\
\hline Coluna Vertebral & Coluna Vertebral & Centro dos Quadris \\
\hline Centro dos Quadris & - & - \\
\hline Quadril Esquerdo & Centro dos Quadris & Joelho Esquerdo \\
\hline Quadril Direito & Centro dos Quadris & Joelho Esquerdo \\
\hline Joelho Esquerdo & Quadril Esquerdo & Tornozelo Esquerdo \\
\hline Joelho Direito & Quadril Direito & Tornozelo Direito \\
\hline Tornozelo Esquerdo & Joelho Esquerdo & Pé Esquerdo \\
\hline Tornozelo Direito & Joelho Direito & Pé Direito \\
\hline Pé Esquerdo & - & - \\
\hline Pé Direito & - & - \\
\hline
\end{tabular}


A Tabela 2 exibe na coluna "Ponto 1" as articulações usadas para calcular os ângulos, e nas colunas "Ponto 2" e "Ponto 3" os outros pontos para que seja possível realizar esse cálculo. Observando a Tabela 2 é possível verificar que as articulações da cabeça, mão esquerda, mão direita, centro dos quadris, pé direito e pé esquerdo são de extremidades, não possuindo a relação entre ângulos e articulações, pois para o cálculo do ângulo são necessários pelo menos três pontos, sendo o ponto central o ponto da articulação que se deseja calcular (TANJI et al., 2013). A Figura 7 mostra o ponto central sendo o Ombro Esquerdo e para calcular seu ângulo é necessário dos pontos Centro dos Ombros e do Cotovelo Esquerdo.

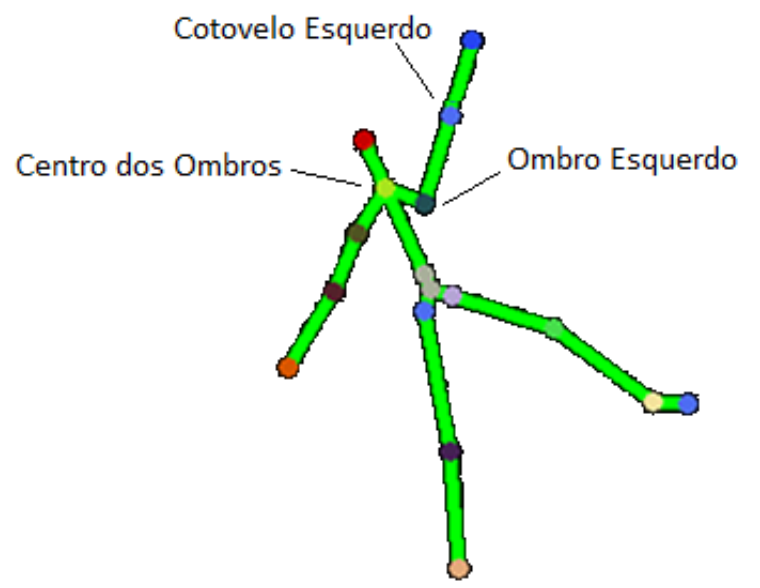

Figura 7. Exemplo de pontos necessários para o cálculo do ângulo.

Fonte: (Autor).

\section{EXPERIMENTOS}

Foram realizados, neste trabalho, alguns experimentos para verificar 0 funcionamento do sistema, se as imagens do sensor Kinect estão sendo exibidas e capturadas da maneira que se espera, se os cálculos dos ângulos de cada articulação estão corretos e se os resultados são coerentes.

Para a execução dos experimentos, primeiramente foram escolhidos alguns exercícios para serem gravados e, posteriormente, executados e testados. Para a escolha dos exercícios e para que os exercícios fossem gravados de forma correta, foi realizada uma investigação em busca de maiores conhecimentos sobre as atividades laborais.

Os exercícios escolhidos para os experimentos foram:

\section{A. Flexão Lateral}

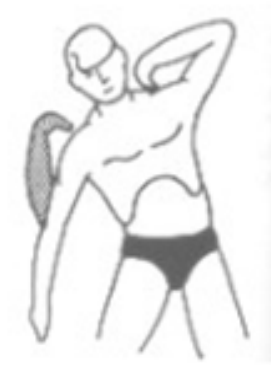

Articulação: Ombro, coluna dorsal e lombar.

Grupos Musculares: Adutores dorsais e lombares.

Entre os exercícios testados, esse foi o que apresentou o melhor resultado. Isso se deve ao fato de que os movimentos realizados para esse tipo de exercício 
conseguem ser capturados de maneira eficiente, além de o exercício ter a possibilidade de ser realizado de modo frontal ao sensor. A Figura 8 mostra um resultado parcial de um movimento, onde é possível comparar as coordenadas $x$ e $y$ e os ângulos de cada articulação.

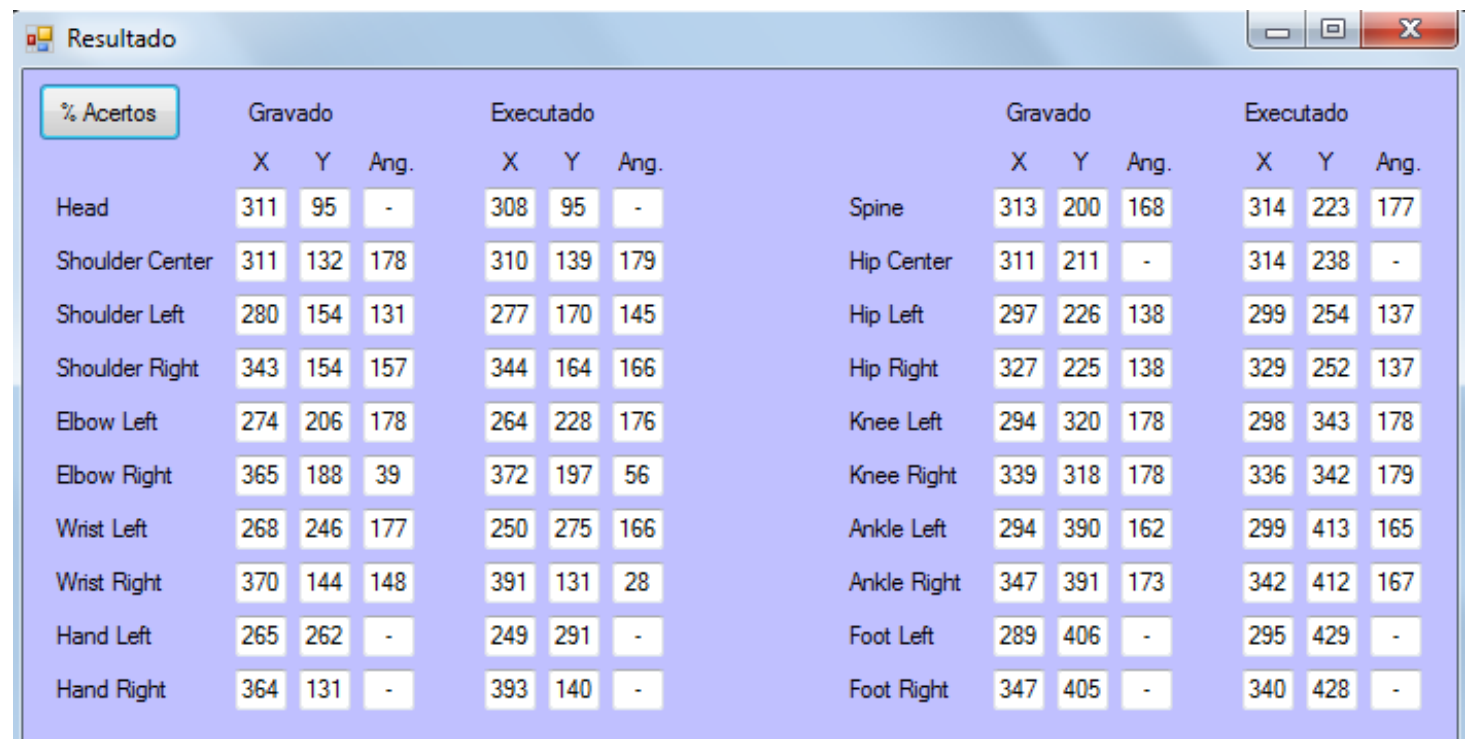

Figura 8. Comparação entre coordenadas $x$ e $y$ e ângulos do que foi gravado e o que foi executado. Fonte: (Autor).

O sistema também fornece resultado em porcentagem para que fique mais fácil para um usuário saber seu desempenho em um exercício.

A Figura 9 mostra a porcentagem de acerto de cada articulação.

\begin{tabular}{|l|}
\hline \multicolumn{1}{|c|}{ \% de Acertos } \\
Centro dos ombros: $99 \%$ \\
Ombro Esquerdo: $87 \%$ \\
Ombro Direito: $94 \%$ \\
Cotovelo Esquerdo: 98\% \\
Cotovelo Direito: $69 \%$ \\
Pulso Esquerdo: $94 \%$ \\
Pulso Direito: $34 \%$ \\
Coluna: $94 \%$ \\
Quadril Esquerdo: $98 \%$ \\
Quadril Direito: $99 \%$ \\
Joelho Esquerdo: $99 \%$ \\
Joelho Direito: $99 \%$ \\
Tornozelo Esquerdo: $97 \%$ \\
Tornozelo Direito: $96 \%$ \\
\\
\\
\end{tabular}

Figura 9. Acertos, em porcentagem, de cada articulação.

Fonte: (Autor).

\section{B. Espreguiçar}

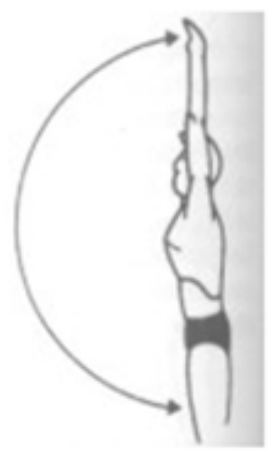

Articulação: Ombro.

Grupos Musculares: Extensores.

Esse exercício não foi possível de ser monitorado pelo sistema, devido à sobreposição dos braços em relação ao corpo. O sistema não consegue mapear todas 
as articulações quando alguma parte do corpo se sobrepõe a outra.

\section{Circundução Lateral}

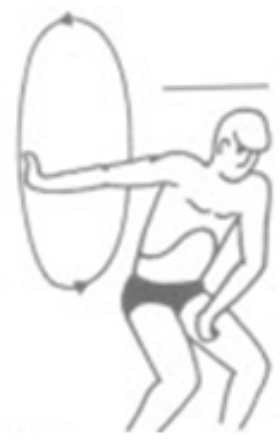

Articulação: Ombro.

Grupos Musculares: Flexores horizontais.

Nesse exercício, o sensor apresentou dificuldades durante o acompanhamento do esqueleto devido ao fato de que o usuário necessita ficar em posição lateral e inclinada.

\section{Flexão Tronco}

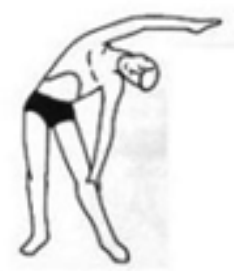

Articulação: Ombro e coluna lombar.

Grupos Musculares: Extensores do cotovelo e adutores do ombro.

O sistema não apresentou dificuldades para acompanhar esse exercício e o resultado obtido após sua execução estava de acordo com o esperado. É mais um exemplo de que exercício frontal e sem sobreposição entre as partes do corpo são os que apresentam os melhores resultados.

\section{Rotação da Cabeça}

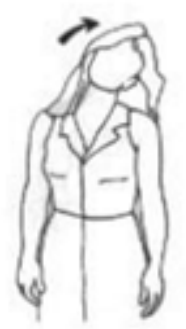

Articulação: Coluna cervical.

Grupos Musculares: Rotadores.

Esse exercício não foi possível de ser acompanhado pelo sistema, pois não é possível calcular o ângulo da cabeça, por se tratar de um ponto de extremidade.

\section{E. Flexão Pernas}

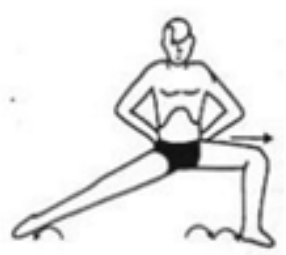

Articulação: Quadril.

Grupos Musculares: Adutores.

O sistema não apresentou dificuldades para o monitoramento desse exercício e o resultado apresentado foi dentro do esperado. Os exercícios de flexão foram os que mais obtiveram resultados positivos.

Após os experimentos foi possível concluir que o sensor Kinect não consegue mapear os pontos que não aparecem na câmera. Exercícios onde o usuário deve ficar 
de lado ou que algum membro fique sobreposto a outro não são possíveis de serem acompanhados pelo sistema.

\section{RESULTADOS}

A partir dos experimentos realizados, foi constatado que existem algumas limitações e que nem todos os tipos de exercícios de ginástica laboral são possíveis de serem cadastrados e acompanhados da forma desejada. Como, por exemplo, quando as partes do corpo que o sensor Kinect não consegue visualizar claramente e são marcadas com o estado de deduzido, isso significa que o sensor Kinect não conseguiu visualizar e mapear corretamente e deduziu um valor. Movimentos em que um membro fique sobreposto a outro também apresenta limitação de funcionamento. Não é possível cadastrar exercícios em que o usuário tenha que ficar de lado e, também, exercícios em que a metade do corpo não fique visível ao sensor Kinect ou que tenha rotações onde algum membro não esteja totalmente visível.

Após realizar o exercício, é possível comparar a posição dos ângulos dos movimentos cadastrados com os movimentos realizados. Também é verificada a porcentagem de acertos em um determinado exercício. Através do sistema ainda é possível visualizar as imagens do rosto do usuário que foram capturadas durante a prática da atividade.
Apesar das limitações citadas, é possível que sejam escolhidos apenas exercícios que o sensor Kinect seja capaz de mapear corretamente, para que dessa forma o sistema tenha um desempenho ideal.

\section{CONCLUSÕES}

Este trabalho possibilitou a integração entre o uso de novas tecnologias e a preocupação do bem estar de pessoas. É evidente que com a utilização do sensor Kinect, funcionários terão maior motivação para a prática de atividades laborais. O sistema apresenta grande utilidade para as empresas, pois é um meio a mais de motivar seus funcionários a realizarem atividades laborais. Além de ser interessante e cômodo para os funcionários, pois permite com que eles possam se exercitar em horários e locais mais flexíveis.

\subsection{Trabalhos Futuros}

Uma melhoria interessante para esse trabalho é que dados entre um computador onde a atividade está sendo realizada e o servidor de uma empresa possam ser recebidos e enviados, por meio de um Web Service. Os dados são em relação às atividades do usuário e poderiam ser armazenados no servidor da empresa para que pudessem ser consultados posteriormente por um profissional da área. Para que seja possível o recebimento dos 
dados por meio de um Web Service, o computador onde o sistema estiver sendo executado deverá estar conectado ao servidor, conforme a Figura 10.

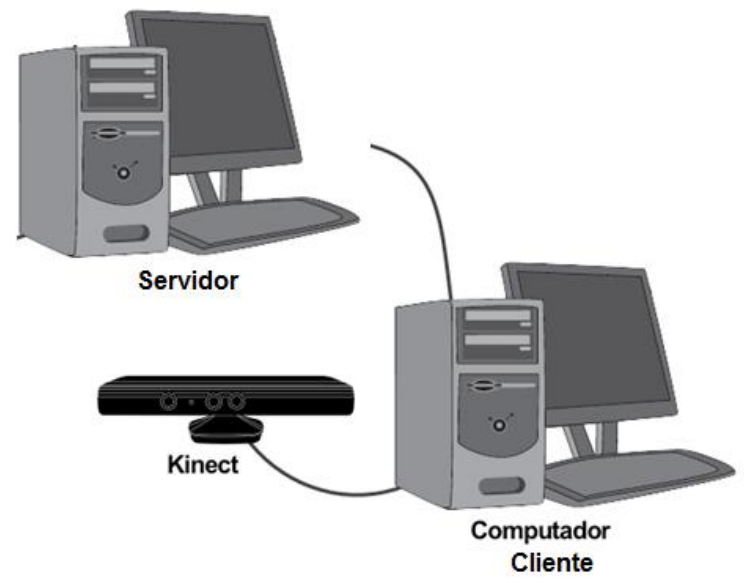

Figura 10. Estrutura física para receber e enviar dados por meio de um Web Service.

Outra melhoria para esse trabalho é descobrir meios para que, adequadamente, seja possível resolver o problema da sobreposição entre as partes do corpo. Esse estudo é interessante devido ao grande número de exercícios de Ginástica Laboral utilizar partes do corpo se sobrepondo umas às outras, o que viria a aperfeiçoar e aprimorar ainda mais o sistema.

\section{REFERÊNCIAS}

ALVES, J. H. F. Ginástica Laborativa: método para prescrição de exercícios terapêuticos no trabalho. Revista Fisioterapia Brasil, v. 1, n. 1, set./out., 2000. p. 19 - 22.

CHANG, Y. C.; CHEN, S. F.; HUANG, J. D. A Kinect-based for physical rehabilitation: $A$ pilot study for young adults with motor disabilities. Research in Developmental
Disabilities, v. 32, n. 6, p. 2566-2570, 2011. http://dx.doi.org/10.1016/i.ridd.2011.07.002

FERRAZ, L. T. D.; YAMASHITA, R. K. S. Desenvolvimento de Jogo Eletrônico para Reabilitação Utilizando um Sensor de Som e Movimento (Kinect). 2012. (Trabalho de Graduação) - Departamento de Engenharia Mecatrônica e de Sistemas Mecânicos, Escola Politécnica da Universidade de São Paulo, São Paulo.

KIMURA, M. N. et al. Ginástica Laboral: uma breve revisão. Buenos Aires: [s.n.], 2010.

LANGE, B. et al. Development and evaluation of low cost game-based balance rehabilitation tool using the Microsoft Kinect sensor. In. ANNUAL INTERNATIONAL CONFERENCE OF THE IEEE EMBS, 33., 2011, Boston. Anais... Boston, Massachusetts, 2011, p. 1831-1834. http://dx.doi.org/10.1109/iembs.2011.60905 $\underline{21}$

LONGEN, W. C. Ginástica laboral na prevenção de LER/DORT?: um estudo reflexivo em uma linha de produção. 2003. 130 f. Dissertação (Mestrado em Engenharia de Produção) - Universidade Federal de Santa Catarina, Florianópolis.

MENDES, R. A.; LEITE, N. Ginástica laboral: princípios e aplicações práticas. São Paulo: Manole, 2004.

PAULA, B. C. Adaptando e desenvolvendo jogos para uso com o microsoft Kinect. of SBGames. In: SBGAMES, 10., 2011, Salvador. Proceedings of SubGame. Salvador: SBC, 2011.

POLITO, E.; BERGAMASCHI, E. C. Ginástica laboral: teoria e prática. Rio de Janeiro: Sprint, 2002. p. 25-76.

SANTOS, C. S. Qualidade de vida nas empresas e a importância da atividade física na organização. Monografia apresenta à 
Universidade Candido Mendes - PósGraduação Latu-Sensu em Gestão Empresarial. Rio de Janeiro, 2008. Disponível em

http://www.avm.edu.br/docpdf/monografias _publicadas/K208973.pdf. Acessada em maio de 2015.

SOARES, G. S.; ASSUNÇÃO, A. A.; LIMA, F. P. A. A baixa adesão ao programa de ginástica laboral: buscando elementos do trabalho para entender o problema. Revista Brasileira de Saúde Ocupacional, São Paulo, v. 31, n. 114, p. 149-160, 2006. http://dx.doi.org/10.1590/S030376572006000200013
TANJI, F. T. K. et al. Uso do Kinect para Monitoramento de Exercícios Físicos Realizados por Pessoas de Terceira Idade. Colloquium Exactarum, Presidente Prudente, v. 5, n. 2, 2013.

XBOX. Apresentando Kinect para XBOX 360 . Disponível em: <http://www.xbox.com/pt$\mathrm{BR} /$ Kinect/Home-new?xr=shellnav $>$. Acesso em: 26 fev. 2013.

ZILLI, C.M. Ginástica laboral e cinesiologia: uma tarefa interdisciplinar com ação multiprofissional. Curitiba: Lovise, 2002. 